\title{
Case Studies on Immediate Implants in Extraction Sockets with Previous Periapical Pathologies
}

\author{
Anwar Dakhil Alabdullah*
}

Damascus-Syria

*Corresponding author: Anwar Dakhil Alabdullah, Damascus-Syria, E-mail: raedmaxfax@yahoo.com

Received: 12 Feb, 2021 | Accepted: 06 Jul, 2021 | Published: 15 Jul, 2021

Citation: Alabdullah AD (2021) Case Studies on Immediate Implants in Extraction Sockets with Previous Periapical Pathologies. J Surg Open Access 7(4): dx.doi.org/10.16966/2470-0991.247

Copyright: (c) 2021 Alabdullah AD. This is an open-access article distributed under the terms of the Creative Commons Attribution License, which permits unrestricted use, distribution, and reproduction in any medium, provided the original author and source are credited.

\section{Abstract}

Objective: The objective of this study is to illustrate several different cases of immediate implants in sockets of previous periapical pathologies that exhibited positive outcomes.

Materials and methods: Presenting four cases, all exhibited periapical lesions of considerable size, and three of them were presented in aesthetic demands. The four cases were managed following thorough granulation tissue removal with copious rinsing resulted with excellent primary stability of the dental implants.

Results: All four cases displayed success in primary stability, aesthetics, and function. Displaying positive outcomes for immediate implant installation in areas of previous periapical lesions. And so, after the follow-up period.

Keywords: Immediate implants; Extraction socket; Periapical lesion; Bone graft

\section{Introduction}

Teeth replacement is a necessity that improves both esthetics and function. Dental implant fame and interest grew exponentially since the publications of the first research papers and clinical trials that advocated the positive outcomes that dental implants acquire. However, only lately immediate implants gained beer fame due to its several advantages, including improved healing, decreased working me as well as surgical procedures. Decreased cost, and patient's discomfort $[1,2]$. Despite its positive qualities, yet it is all considered to be a highly controversial topic, especially if they are involved in extraction sockets of periapical lesions [1]

Traditional implants advocated by Brånemark suggest that implant is preferred to be placed after 12 months of extraction. An average of $40 \%-60 \%$ of original bone height and width is expected to be lost after tooth extraction [3]. Not only this traditional method prolongs the healing and the return of esthetics and function, but it can definitely increase the cost to the parent as well [4].

To comprehend the concept of immediate implant technique, we ought to understand the foundation first and this descends to the meaning of osseointegration which was initially described by Brånemark as the direct structural and functional link between the bone and the Surface of the implant. To achieve a successful osseointegration it is highly recommended to maintain a stress-free healing period [2].

It is known that tooth extraction inherently leads to alveolar bone loss in height and width, and it is even more pronounced in the anterior maxilla where ridge resorption creates an unfavorable palatolabial discrepancy between implant and prosthesis [4].

Therefore, in this study, we aim to enhance the success of immediate implant movement by illustrating different cases of immediate implants in sockets of previous periapical lesions and most of them with esthetic demands that showed successful results even after follow up.

It has been reported by several research papers and clinical experiments that immediate implants placement into extraction sockets exhibiting periapical pathologies can be employed successfully with consideration of preoperative measures, including antibiotics, meticulous cleaning and irrigation, bone debridement, so tissue curettage and post-operative regular check up [5] if these measures are considered and conducted carefully without negligence; immediate implant placement will certainly yield positive outcomes.

This study illustrates the full procedure of four different immediate implant cases with periapical lesions of considerable sizes and three of them display an aesthetic demand and how these cases showed successful outcomes by the end of the treatment and after the following up intervals.

\section{Case 1}

The upper leg and right lateral incisors were indicated for extraction due to periapical lesions diagnosed by radiographs. Immediate implant, open flap surgery was planned due to adequate clinical features, oral hygiene instructions and proper scaling and 
root planning to maintain excellent plaque control. A cone beam CT scan was performed to obtain a 3-dimensional picture. A preoperative Antibiotic was prescribed one day before the surgery for 10 days (Augmentin 1g). Surgery was initiated with local anesthesia, lidocaine $1 / 100,0002 \%$. After a muco-periosteal flap was raised the two lateral incisors were extracted followed by granulation tissue removal, then the area was copiously irrigated with normal saline. The sockets were prepared for immediate implant placement $11 \mathrm{~mm}$ length and $3.5 \mathrm{~mm}$ in diameter (CAMLOG, Germany).The two lateral immediate implants were placed $2-5 \mathrm{~mm}$ from the buccal bone and anchored to the nasal floors. Then a periapical radiograph was taken (Figure 1). A sticky bone graft was placed on the lesion cavies followed by 2 .
Platelet rich fibrin obtained from the Patient's own blood placed on the sky bone. Surgical site was then closed by resorbable sutures.

\section{Case 2 Reem (47)}

The lower right second molar was indicated for extraction due to large endo-perio lesions diagnosed by the periapical radiographs. After oral hygiene instructions followed by scaling and root planning, a cone-beam CT scan was performed to obtain a 3-dimensional image of the surgical site. Immediate implant, open flap surgery was planned. The tooth was extracted with the previously mentioned antibiotics course. A muco-periosteal flap was raised to facilitate tooth extraction with the removal of the endo-perio lesion. Careful surgical curettage followed by Laser was used to confirm removing all the remaining
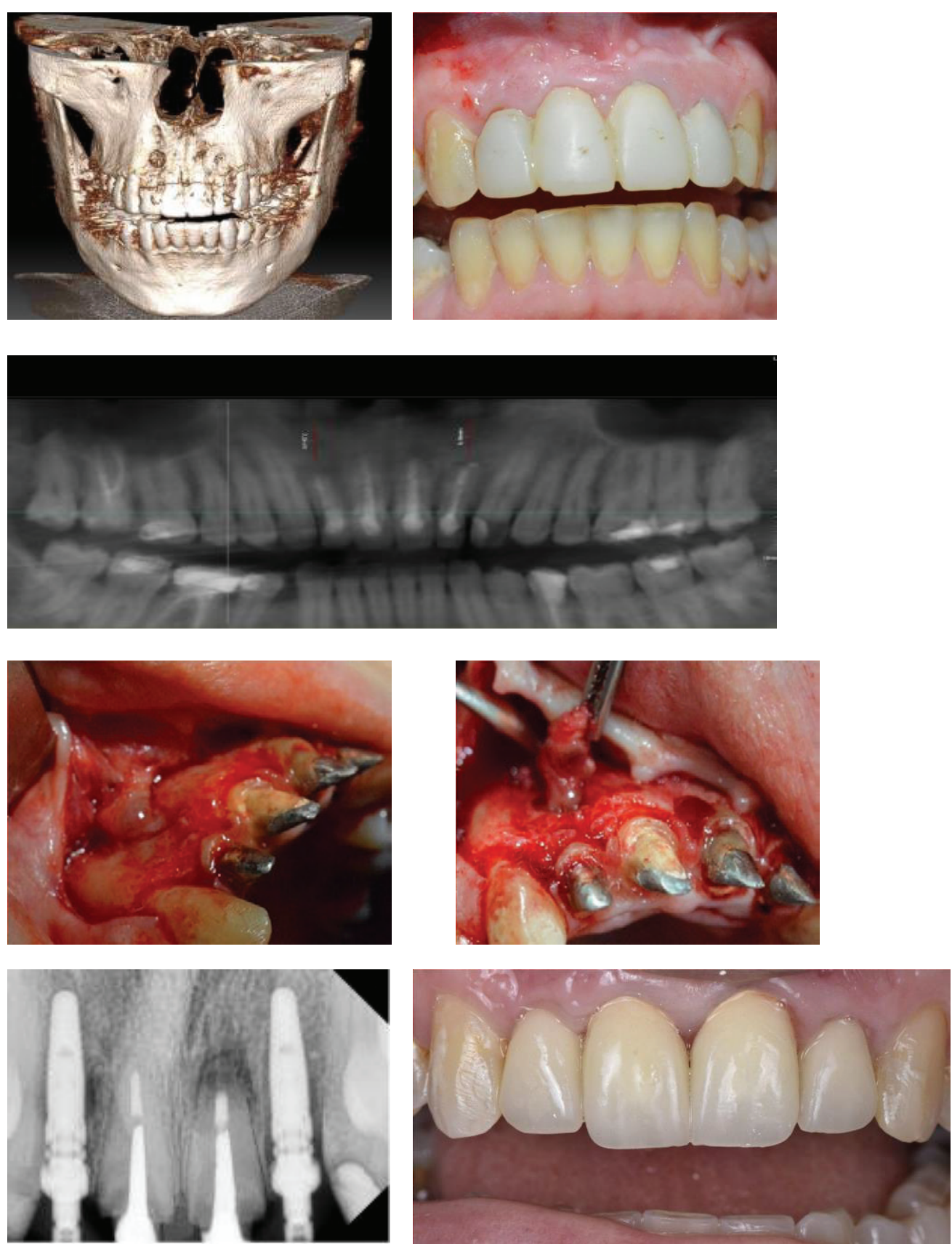

Figure 1: Case 1 


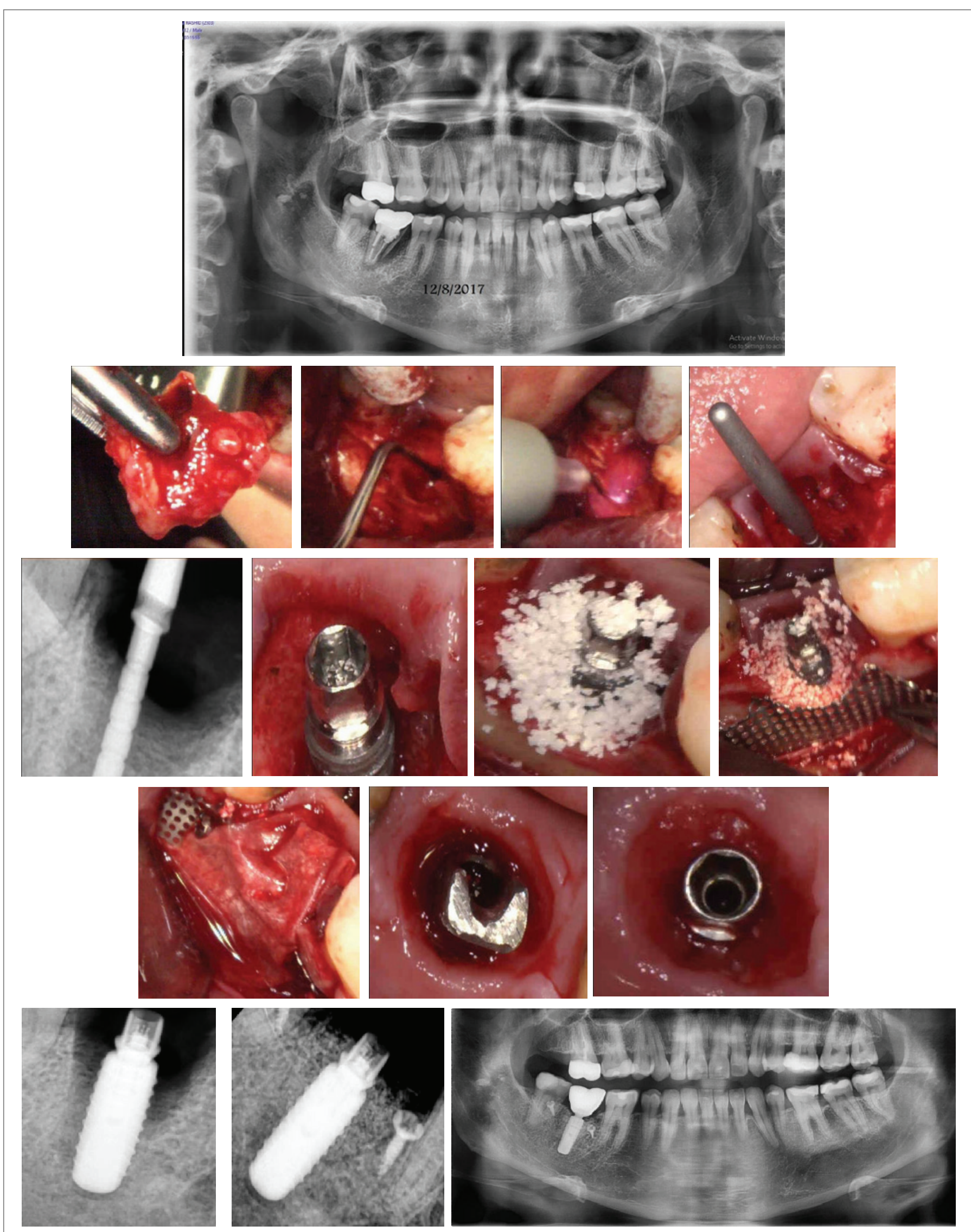

Figure 2: Case 2 
granulation tissues then with normal saline irrigation, hence the surgical site is ready for immediate implant loading. The manual was placed in the socket to ensure socket length then socket preparation was performed according to manufacturer's instructions $\left(11^{\star} \mathrm{mm}\right.$ length $5 \mathrm{~mm}$ diameter). The Implant was placed intra-radicular intact bone followed by a periapical radiograph to ensure location (specify figure 2). Since the bone around the implant was insufficient a sticky bone graft was placed (specify type \& brand) on the implant and socket peripheries followed by a non-resorbable and a resorbable membrane [specify types and Brand] with mini screws fixations to ensure good stability. Then the flap was closed by resorbable sutures to ensure the area was sterile and intact (Figure 2).

\section{Case 3}

The upper right lateral incisor was indicated for extraction due to a periapical lesion of a considerable size diagnosed by radiographs. After the rise of muco-periosteal flap and removal of crowns. The tooth was extracted, and the periapical lesion was removed. After careful curettage and normal saline irrigation, a $13 \mathrm{~mm}$ length, $3.8 \mathrm{~mm}$ in diameter immediate implant was installed (CAMLOG ${ }^{\circ}$, Germany). The implant was placed $2 \mathrm{~mm}$ to the buccal bone and anchored on the nasal floor, followed by bone graft (NuOss DS cancellous anorganic bovine bone $50 \mathrm{cc}$ syringe particle size $25-1 \mathrm{~mm}$ ). The area was closed by sutures and the previous crown was re-cemented back as a temporary crown (Figure 3).

\section{Case 4}

The upper right incisors with the first premolar were indicated for extraction due to periapical lesions diagnosed from periapical radiographs. A muco-periosteal flap was opened to facilitate teeth extraction accompanied with the removal of periapical lesions was accomplished with precise debridement and surgical curettage of the sockets followed by normal saline irrigation. The socket peripheries were then examined and considered to be adequate for immediate implant loading. The manual was placed in each socket then socket preparation was carried out according to manufacturer's instructions $3.8 \mathrm{~mm}$ diameter, $11 \mathrm{~mm}$ length for centrals while $3.3 \mathrm{~mm}$ diameter, $13 \mathrm{~mm}$ length for the first premolar (CAMLOG ${ }^{\circ}$, Germany). The central implants were placed $2-3 \mathrm{~mm}$ from the buccal bone and anchored on the nasal cavity while the premolar implant was placed $1 \mathrm{~mm}$ on the buccal bone and anchored on the sinus floor. the apical alveolar bone was thinner than the coronal alveolar bone due to the periapical lesions removed so a sticky bone graft was placed on the lesions to compensate the amount of bone loss accompanied with decoration on the buccal wall then a resorbable collagen membrane was placed
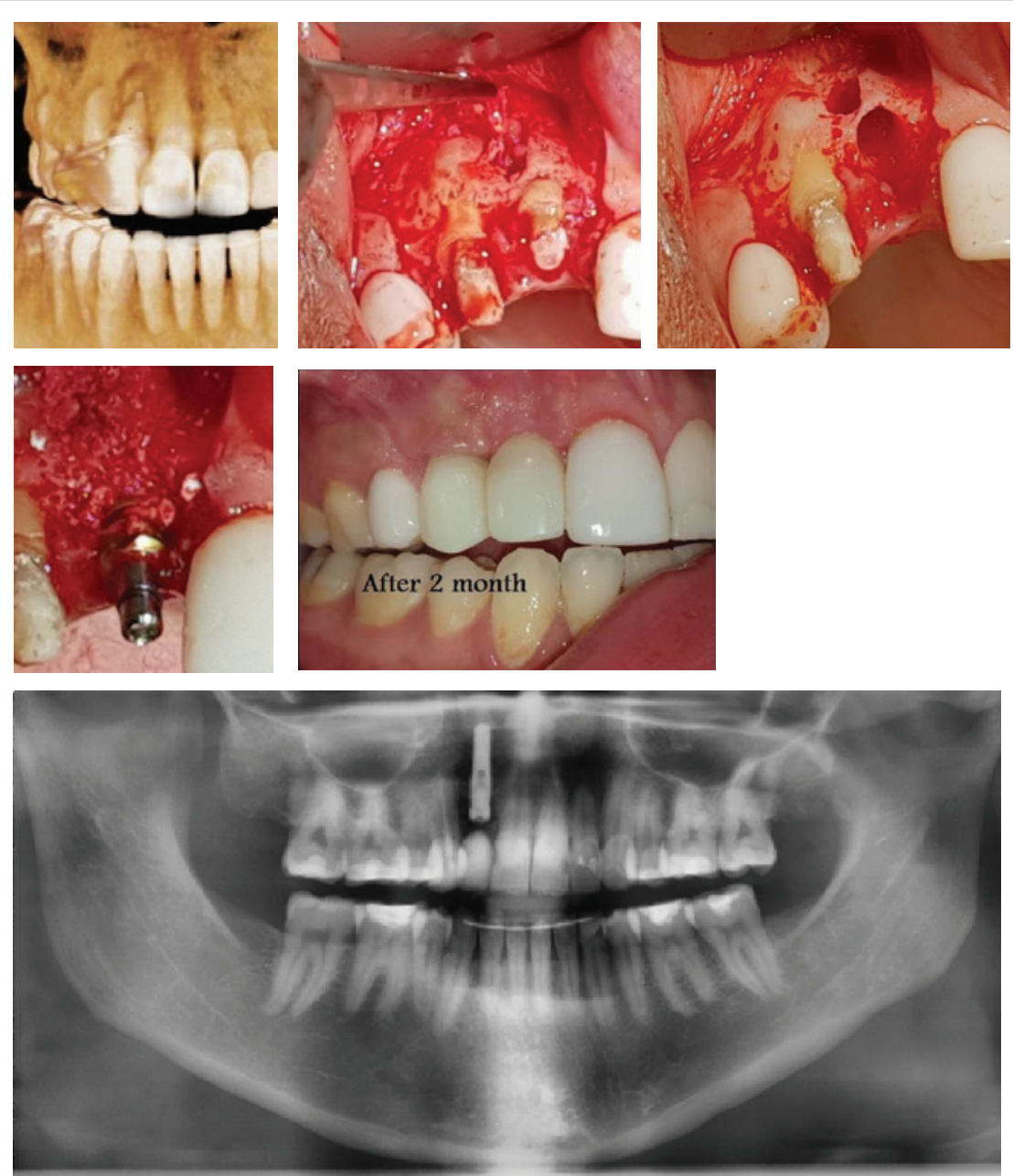

Figure 3: Case 3 


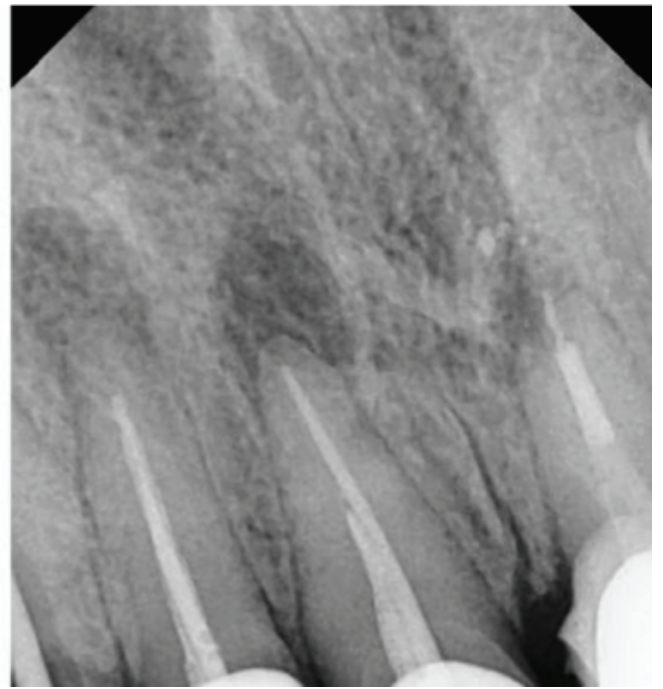

Figure 4: Case 4

over the sky bone then fixed with mini screws to keep them in place. At last, the old bridge was recemented and was kept temporary for three months, the minimum period needed for osseointegration to be successful (Figure 4).

\section{Discussion}

It has been recommended, that immediate implant placement in extraction sockets of previous periapical lesions is contraindicated because it might conflict with the osseointegration and inhibit the whole implant therapy procedure from survival however, when we understand the term osseointegration and how to attain it, we come to grasp firmly the meaning of a successful implant therapy that can be increased by a stress-free nonfunctional healing period [6-8].

It's believed that with appropriate knowledge and experience, the outcome of immediate implants in sockets of periapical lesions can be positively accomplished. Yet pre-operative measures are very crucial in giving auspicious outcomes of immediate implant procedure including, choosing the right patient with good oral hygiene, preoperative antibiotic treatment.

Meticulous bone debridement and irrigation, guided bone regeneration to compensate for socket deficiencies and postoperative follow up $[9,10]$.

\section{Our protocol includes}

1. Medication therapy consists of Augmentin $1 \mathrm{gm}$ with metronidazole $500 \mathrm{mg}$ and Cataflam $100 \mathrm{mg}$ as painkiller.

2. A traumatic extraction.

3. Removal of periapical lesions.

4. Irrigation and debridement of bone. Includes removing $1 \mathrm{~mm}$ of bone with round bur after removal of periapical lesion to prevent lesion recurrence and to eliminate any further implant or bone inflammation.

5. Diode laser to ensure socket decontamination. It has been suggested that Diode laser has a bactericidal action according to some studies that regard bone regeneration by several mechanisms that increase the differentiation of mesenchymal cells into osteoblasts therefore accelerates osteogenesis [11].
6. Guided bone regeneration.

7. Implant Insertion with torque ( $35 \mathrm{Ncm}$ manual torque).

8. Suture.

9. Temporary crown if applicable.

Since the initial purpose of immediate implant therapy is to maintain esthetics and function then we can evaluate the success of our immediate implant therapy by evaluating the results on ethics and function and after follow-up intervals which showed positive results on these two aspects from both practitioner and parent's view.

\section{Despite all those four cases that we presented with success there are still some authors against the immediate implants because of the following complications}

Poor implant poisoning, gingival recession, membrane exposure during healing phase and unacceptable esthetic results [12-16].

\section{Conclusion}

Immediate implant placement in extraction socket exhibiting periapical infections with esthetics demands can certainly show satisfactory functional and esthetic results however with preoperative antibiotic course and following through granulation tissue debridement and irrigation procedures along with operator's knowledge and experienced skills with using Guided bone regeneration can give auspicious outcomes.

\section{References}

1. Novaes AB Jr, Muglia VA, Ramos UD, Reino DM, Ayub LG (2013) Immediate implants in extraction sockets with periapical lesions: an illustrated review. J Osseointegrat 5: 45-52.

2. Nizar AA, Jacob CA, Nila PP (2017 Immediate Placement of Zirconia Implants in Teeth with Periapical Lesions: A Case Report. J Clin Diagn Res 11: ZD26-ZD28.

3. Sabir M, Alam MN (2015) Survival of Implants in Immediate Extraction Sockets of Anterior Teeth: Early Clinical Results. J Clin Diagn Res 9: ZC58-ZC61.

4. Siegenthaler DW, Jung RE, Holderegger $C$, Roos $M$, Hämmerle $C H$ (2007) Replacement of Teeth Exhibiting Periapical Pathology by Immediate Implants: A Prospective, Controlled Clinical Trial 18: 727737.

5. Álvarez-Camino JC, Valmaseda-Castellón E, Gay-Escoda C (2013) Immediate implants placed in fresh sockets are associated with periapical infectious processes. A systematic review. Med Oral Patol Oral Cir Bucal 18: e780-e785.

6. Bell CL, Diehl D (2011) The immediate placement of dental implants into extraction sites with periapical lesions: a retrospective chart review. J Oral Maxillofac Surg 69: 1623-1627.

7. Casap N, Zeltser C, Wexler A, Tarazi E, Zeltser R (2007) Immediate placement of dental implants into debrided infected dentoalveolar sockets. J Oral Maxillofac Surg 65: 384-392.

8. Truninger TC, Philipp AO, Siegenthaler DW, Roos $M$, Hämmerle $\mathrm{CH}$, et al. (2011) A prospective, controlled clinical trial evaluating the clinical and radiological outcome after 3 years of immediately placed implants in sockets exhibiting periapical pathology. Clin Oral Implants Res 22: 20-27.

9. Naves MM, Horbylon BZ, Gomes CF, Menezes HH, Bataglion C, et al. (2009) Immediate implants placed into infected sockets: a case report with 3-year follow-up. Bra Den J 20: 254-258. 
10. Muhamad A-H, Georges C, Azzaldeen A (2017) Immediate Implants Placed Into Infected Sockets: Clinical Update with 3-Year Follow-Up. IOSR J Den Med Sci 16: 105-111.

11. Waasdorp JA, Evian Cl, Mandracchia M (2010) Immediate placement of implants into infected sites: a systematic review of the literature. J Periodontol 81: 801-808.

12. Giri D, Kundapur PP, Singh VP (2013) Immediate implants in dentistry: a review. 33: 449-454.
13. Yadav S, Nawal RR, Talwar S, Verma M (2020) Low-level laser therapy for management of large periapical lesions associated with open apex cases. Indian J Dent Res 31: 334-336.

14. Froum SJ (2015) Dental Implant Complications. Wiley: 736.

15. Askary AESE (2008) Fundamentals of Esthetic Implant Dentistry. Wiley: 226-216.

16. Jokstad A (2009) Osseointegration and Dental Implants. Wiley: 448. 